\title{
COMMUNICATING MIS RESEARCH: A CITATION STUDY OF JOURNAL INFLUENCE
}

\author{
RANDOLPH B. COOPER \\ College of Business Administration, University of Houston, \\ Houston, TX 77204, U.S.A. \\ DAVID BLAIR \\ School of Business Administration, The University of Michigan, \\ Ann Arbor, MI 48109, U.S.A. \\ and \\ Miranda Pao \\ School of Information and Library Studies, The University of Michigan, \\ Ann Arbor, MI 48109, U.S.A.
}

(Received 18 October 1991; accepted in final form 28 January 1992)

\begin{abstract}
Due to difficulties with objectively evaluating the quality of MIS research, attitudes about journals in which this research is published play an important role in determining the allocation of research resources. To provide a more objective basis for these attitudes, we examine journal influence in communicating MIS research over a 9-year period using citation analyses, researcher perceptions, and publishing patterns of top MIS research universities. As a result of these analyses, we identify a cohesive stable group of highly influential journals which can reasonably be called an MIS core. An internal ranking of this core is then determined which is significantly different from prior rankings.
\end{abstract}

\section{INTRODUCTION}

Perceptions of research quality are central to the allocation of resources within the research community, affecting (Doreian, 1988):

- Expansion or contraction of university schools and departments.

- Promotion, tenurc, and salary of faculty.

- Research grant awards.

Due to the difficulty of evaluating research quality, such evaluations are heavily influenced by attitudes concerning the journals publishing the research articles. For example, a journal's influence in communicating research typically outweighs any evaluation of an article's content because resource allocation decisions are frequently made by people outside the individual's discipline (Coe \& Weinstock, 1984). This difficulty is compounded by the fact that the importance of research may not be apparent for some years after publication. [Hamilton \& Ives (1982) found the modal and median elapsed time between MIS article publication and MIS article citation to be about 2 and 4 years, respectively.]

Given the importance associated with journal influence, attempts have been made to provide an empirical basis for MIS journal influence rankings. For example, Vogel and Wetherbe (1984) examined the publishing preferences of leading MIS research institutions. However, most journal influence evaluations use surveys of MIS academics and practitioners (Hamilton \& Ives, 1983; Doke \& Luke, 1987; Stohr, 1987; Koong \& Weistroffer, 1988). This work has led to some consensus in perception of journal influence. For example, MIS Quarterly, Communications of the ACM, and Management Science are consistently among the top 10. Unfortunately, there exist many more conflicts both in the identification of top paper

The authors gratefully acknowledge helpful comments provided by Mary Culnan on earlier drafts of this

Correspondence should be sent to Dr. Cooper. 
journals, as well as the ranking of those journals. This is illustrated below by rankings of the top 10 journals (in descending order), as indicated by the publishing records of the top 5 MIS publishing institutions (Vogel \& Wetherbe, 1984), a citation analysis of MIS article use (Hamilton \& Ives, 1983), and a survey of MIS academics' perceptions of importance/prestige (Doke \& Luke, 1987):

\section{Vogel and Wetherbe}

1. Communications of $A C M$

2. Harvard Business Review

3. MIS Quarterly

4. Information and Management

5. Sloan Management Review

6. Management Science

7. Journal of Data Education

8. Datamation

9. Data Base

10. Trans on Database Systems

\section{Hamilton and Ives}

Management Science
Datamation
Harvard Business Review
Communications of ACM
Journal of Sys Mgmt
Data Base
IBM Systems Journal
MIS Quarterly
Information and Management
Computing Surveys

Doke and Luke

MIS Quarterly
Communications of ACM
Journal of MIS
Omega
Management Science
Journal of CIS
Datamation
Journal of ISM
Journal of Syst Mgmt
Journ of Am Stat Assn

Information and Management includes Systems, Objectives, and Solutions. The discrepancy among these rankings is evidenced by the existence of only four common journals and insignificant correlations among the rankings (see Table 1).

Problems with journal ranking may result from complexities associated with the concept of journal influence as well as with measurement biases. For example, influence includes the following dimensions (Hamilton \& Ives, 1983; Garfield, 1972):

1. Content of communication: news-oriented vs. original research-oriented.

2. Audience: academic vs. practitioner.

3. Extent of communication: readership volume (journal circulation).

4. Quality of communication:

- Influence of research through actual use of articles.

- Perceptions of article influence.

With the focus of this article upon perceptions of research quality within the research community, a journal's influence will be greater if it is original research-oriented and addresses an academic rather than a practitioner audience. In addition, from this perspective, readership volume is important to the extent that it affects the actual use of articles in research and that it affects perceptions of article influence by people in the academic community. Thus, overall journal influence rankings from a research perspective should be derived from the actual use of articles in research and from perceptions of article influence by researchers.

In response to these conceptual issues, Hamilton and Ives (1983) created a single ranking of MIS journal influence in terms of actual article use and researcher perceptions. We believe that their approach is reasonable but have reservations concerning their resultant ranking. These reservations are based upon the following concerns:

Table 1. Spearman correlations comparing three rankings

\begin{tabular}{lcc}
\hline & V \& W & D \& L \\
\hline H \& I-CIT & .21 & -.08 \\
V \& W & & -.08 \\
\hline
\end{tabular}

When correlating two sets of journals, journals which are in set $A$ but not in set $B$ are given the lowest rank in set $B . N$ varies between 13 and 16 depending upon the commonality of journals between two sets. All correlations are insignificant at alpha $=.01$.

H \& I-CIT: Hamilton and Ives (1983) top 10 ranking based upon their citation analysis; V \& W: Vogel and Wetherbe (1984) top 10 ranking based upon the publishing records of the top five MIS publishing institutions; D \& L: Doke and Luke (1987) top 10 ranking based upon a survey of MIS academics' perceptions of importance/prestige. 
1. Does a core of MIS journals actually exist? That is, given the diversity of MIS research, is there a cohesive group of journals which strongly influence MIS research? If this is not the case, then a single ranking of journal MIS influence is not appropriate. Rather, there should be one ranking for each MIS subfield.

2. If the core exists, is it stable over time? There are many claims that the MIS field is young and changing; do these changes affect the membership and ranking of journals in the MIS core over time? With the time lags between a paper's acceptance, its publication, and its evaluation for promotion, tenure, etc., unstable rankings may provide poor evaluation criteria as well as provide poor guides for paper submission.

If a core exists and it is relatively stable over time then it is reasonable to determine a priority ranking among the core journals in terms of research influence. We examine these issues next and do find the existence of a stable core. We then conclude by determining a ranking of journals within this core using a methodology which tends to be less biased and more appropriate for our purpose (identifying journal influence of MIS research) than the Hamilton and Ives methodology.

\section{THE EXISTENCE OF AN MIS CORE}

The existence of an MIS core is equivocal (Culnan \& Swanson, 1986). For example, Culnan's (1987) empirical analysis indicates that MIS research can be divided into five diverse subfields: (1) foundations; (2) individual approaches to MIS design and use; (3) MIS management; (4) organizational approaches to MIS design and use; and (5) MIS curriculum. However, her work also indicates that MIS authors publish in multiple subfields (over $50 \%$ of the authors she studied published in two or more subfields) and that frequently cited articles representing the subfields tend to be published in the same set of journals:

- Management Science is represented in subfields 1, 2, and 3.

- Harvard Business Review is represented in subfields 1 and 3.

- MIS Quarterly and Decision Sciences are represented in subfields 1 and 2.

- Subfield 4 has only one article and subficld 5 has none.

That MIS authors publish in multiple subfields and the coverage of MIS research diversity by a few journals supports the notion of an MIS core.

This is further supported by Hamilton and Ives (1982), who found that $87 \%$ of the most frequently cited articles between 1970 and 1979 were published by Harvard Business Review, Management Science, Communications of the ACM, and Sloan Management Review, and by Culnan (1987) who found that these journals plus MIS Quarterly, Decision Sciences, and Interfaces included $90 \%$ of the frequently cited articles between 1980 and 1985. We thus have a reasonable expectation that there exists a cohesive core of influential journals which publish articles over the range of MIS topics.

\subsection{The methodology: citations analysis}

Two necessary conditions for an MIS research core are that its member journals strongly influence MIS research and that its member journals are cohesive (i.e., interdependent). In order to identify journals which meet these conditions, we employ the power of citation analysis which is based upon the actual use of articles in research.* There are many different kinds of citation analyses which can be employed (Doreian, 1988; Garfield, 1972). For example, influential journals can be identified by the number of citations to their articles by articles in a set of other journals which reasonably cover the research area (Hirst, 1978). Though there are difficulties associated with this approach (Moravcsik \& Muruge-

\footnotetext{
*The methods used here represent one of various alternatives for determining the MIS core. However, each alternative has its own set of problems. For example, Rice and colleagues (Rice, Borgman, Bednarski, \& Hart, 1989; Rice, 1990) describe reliability problems when relying on the Journal Citation Report. Problems with our approach are discussed in this article.
} 
san, 1975), there is evidence that such analysis is a reasonable way to judge journal influence through use (Garfield, 1972; Smith, 1981; Jensen, Long, Smith, Stulz, \& Warner, 1987). Journal cohesiveness can be measured, for example, by determining the effect of each journal upon the amount of communication entropy (disorder) existing in a system of journals publishing articles on the same subject (Shaw, 1981, 1983; Pao, 1980; Boyce \& Martin, 1981).

Citation analysis is an unobtrusive way to judge the influence of research within the research community. Such analyses do not require cooperation of respondents and thus are not prone to many of the biases associated with eliciting researcher perceptions (e.g. rating journals highly in order to promote an individual's publishing record) and the noise which can be introduced due to multiple perceptions of influence criteria.

However, there still exists the potential for significant bias in the results of a citation analysis journal ranking. For example, bias due to uneven knowledge of journals can significantly affect citation analyses because articles in unknown journals will not be highly cited. In addition, the following sources of bias may be important (Hirst \& Talen, 1977; Salton \& Bergmark, 1979; Servi \& Griffth, 1980):

1. Over time, new journals begin and old journals stop publishing. In addition, journals may change focus as a result of editorial policy changes.

2. Journal circulation and coverage of secondary indexing and abstracting services influence citation rates.

3. A few articles that are highly cited may distort a journal's average citation rate.

4. Older, established journals tend to have more citations than new journals.

5. Journal self-citation (articles in one journal citing other articles in the same journal) can influence citation rates.

6. Journals which publish a large number of articles per year have a greater chance of attracting citations than those which publish only a few articles per year. In addition, journals publishing a large number of articles per year may have a larger number of citations to other journals.

This list arranges the biases in order of their ability to be dealt with in a research design, with number 1 the hardest and 6 the easiest to compensate for. The impact of the first two may be significant and are addressed by conclusions of this study. MIS journals have stopped publishing and have combined (e.g. the combining of Information and Management and Systems, Objectives, Solutions) and new journals have begun (e.g. Journal of MIS, Journal of Information Resource Management Systems, and Information Systems Research). Journals are also changing their editorial policies in order to include a wider spectrum of MIS articles (e.g. Communications of the ACM and Information Processing and Management). Regarding Bias 2, many of the MIS-related journals are either not on secondary indexing services or have just recently been included (e.g. Journal of MIS and MIS Quarterly). Bias 3 is not necessarily a negative factor; because journals should be judged based upon influence of articles as well as quantity, a few highly cited articles does indicate one dimension of journal influence. Bias 4 can be reduced by choosing an appropriate citation time frame within which all journals of interest are available. Bias 5 and 6 can be eliminated by not counting self-citations and by normalizing citations based upon the number of articles in a journal.

There have been previous MIS citation analyses. Culnan $(1986,1987)$ performed cocitation analyses of the MIS literature from 1972 to 1982 and then from 1980 to 1985 . The purpose of her analyses were to identify (changes in) intellectual subfields in MIS and the reference disciplines within which these subfields are grounded. Culnan and Swanson (1986) examined articles from 1980 to 1984 in order to assess the emergence of MIS as an independent scholarly field of study - as differentiated from the referent fields of computer science, management science, and organizational science.

However, the only citation work aimed solely at identifying the MIS core was done by Hamilton and Ives (1983). Their ranking (illustrated in the introduction) was based upon citations from MIS articles published in 1979. There is a need for further work in this area 
for at least two reasons. First, the MIS field is expanding and changing. This is reflected by changing research emphases, changing editorial policies of existing journals, and the emergence of new journals. It is reasonable to get more current citation data in order to check the stability of the MIS core. Second, the citation analysis which resulted in their ranking was relatively simple and had the following methodological limitations:

- Data were gathered only from publications which occurred in 1979. This may introduce bias due to anomalous events specific to 1979 which may limit its generalization.

- Journal self-citation influences were not accounted for (Bias 5, above). This may result in inflated rankings for journals with "self-contained research streams."

- The influence of the differing number of articles per journal was not accounted for (Bias 6, above). Thus, for example, a lower influence journal which receives one citation per article may be ranked the same as a higher influence journal which receives 10 citations per article but publishes one-10th as many articles.

- The power of sophisticated and more informative bibliometric techniques was not exploited. These techniques can be used to obtain greater insight into journal influence and cohesion.

In overcoming these limitations, this study builds upon the Hamilton and Ives work to provide a more sophisticated and less biased analysis of MIS journal research influence and cohesion.

\subsection{Identifying influential journals}

Prior to analyzing citations, articles from which citations are gathered must be identified. Typically, bibliometric studies retrieve articles through the use of key word searches on databases such as ABI/INFORM or through citation linkages within citation indices such as the Social Science Citation Index (Garfield, 1972). Unfortunately, these are not feasible for a MIS study. The interdisciplinary nature and relative youth of the MIS field make it hard to identify a reasonable set of key words which would not exclude many relevant articles and which would not include many irrelevant articles. In addition, due to MIS's youth, many MIS journals are not included (or have only recently been included) in citation indices. Using these indices would thus exclude many relevant articles from examination.

Thus, the approach taken here is to use a set of MIS research articles which have been shown to reasonably cover the breadth of MIS topics from 1981 through 1985 . Such a set of articles can be obtained from a MIS literature review by Cooper (1988), which included 146 journal articles from 26 journals covering subjects such as: management of the information resource; information systems technology and corporate strategy; analysis; design; programming; office automation; model management systems; information retrieval; impact of information systems on individuals and the organization; decision support systems, etc. These articles made a total of 2272 citations to 294 different journals. ${ }^{*}$ Note that the term journal is used here to represent any serial publication which includes academic refereed publications (such as Management Science), practitioner publications (such as Datamation), and conference proceedings (such as the ICIS Proceedings). This approach is used, rather then limiting journals to academic refereed publications, to reduce the impact of $a$ priori notions of journal influence and let the data indicate actual influence patterns.

Including all 294 different publications in an analyses would inhibit rather than aid in understanding MIS journal influence. For example, many of the publications do not pub-

*The article by Cooper was chosen because it is one of the most comprehensive recent reviews of the MIS literature. Though any citation study can be biased by the initial articles it uses, we feel that this bias is negligible here because (1) of the variety of topics covered in the review, (2) of the large number of different journals (26) represented in the review, (3) we gather articles in addition to those in the review during later stages of our analysis, and (4) it has been shown by Goffman (1985) and Goffman and Pao (1980), that when focusing upon the most influential journals, initial journal bias decreases quickly when using subsequent generation citations.

Note that the 2272 citations does not represent the number of unique articles cited because some articles may have been cited more than once. 
lish MIS articles; rather, they are psychology, sociology, or economics journals referenced for methodological purposes. In order to reduce the number of journals to a reasonable size, the 294 journals are ranked in order of the number of times they have been cited by the original 146 articles in Cooper's review. This forms a relatively simple influence ranking and a subset of highly influential journals can then be chosen from the top of this ranking. Unfortunately, the simplicity of this ranking can introduce significant bias, as was present in the Hamilton and Ives (1983) study. To overcome this bias, four different ranking schemes are used:

1. Raw citation scores including self-citations.

2. Raw citation scores excluding self-citations.

3. Normalized citation scores including self-citations.

4. Normalized citation scores excluding self-citations.

(Normalization is achieved by dividing the citations made from journal $\mathrm{A}$ to journal $\mathrm{B}$ by the number of articles doing the citing in journal A.)

The combination of these different rankings overcome the first three limitations of the Hamilton and Ives (1983) study. That is, all rankings include data from multiple years in order to reduce the impact of anomalies associated with a single year. These rankings also minimize the possible bias of self-citation by calculating rankings both with and without self-citations. Finally, the possible bias of raw vs. normalized scores is addressed by calculating the journal rankings both ways in order to reduce any bias caused by certain journals publishing more MIS articles per year than other journals. Since there is no a priori reason to prefer one ranking scheme over another, they all are used to choose an unranked set of journals for further consideration.

Table 2 illustrates the results of these ranking schemes. The union of the top 10 journals from these four rankings results in a total of 14 top journals. This is a sufficient number of journals on which to base our study as supported by the fact that over $45 \%$ (1026) of all the references made by the original 146 articles were to these 14 journals. Thus, it is reasonable to assume that the following 14 journals (arranged alphabetically) includes the most influential core MIS journals:

- Academy of Management Journal

- Administrative Science Quarterly

- Artificial Intelligence

- Communications of the ACM

- Data Base

- Datamation

- Decision Sciences

- Harvard Business Review

- Interfaces

- Journal of Documentation

- Journal of the American Society for Information Science

- Management Science

- MIS Quarterly

- Sloan Management Review

That the MIS core is contained within these 14 journals is also supported by Hamilton and Ives (1982) who found that $87 \%$ of the most frequently cited articles between 1970 and 1979 were published by journals in this list and by Culnan (1987), who found that $90 \%$ of the frequently cited articles between 1980 and 1985 were published by journals in this list.

The next step is to determine which of the 14 journals fulfill the second MIS core requirement: cohesion. Journals that belong in such a core should contain research which is relatively interdependent in terms of a mutual research influence. Two methods are used to evaluate this cohesion. The first analyzes the influence each journal has upon the other 
Table 2. Ranking of the top 15 journals from four different perspectives

Ranking based upon raw citation scores including self-citations

$\begin{array}{lr}\text { 1. Management Science } & 213 \\ \text { 2. MIS Quarterly } & 189 \\ \text { 3. Harvard Business Review } & 130 \\ \text { 4. Communications of the ACM } & 116 \\ \text { 5. Administrative Science Quarterly } & 63 \\ \text { 6. Datamation } & 63 \\ \text { 7. Sloan Management Review } & 48 \\ \text { 8. Database } & 47 \\ \text { 9. Decision Sciences } & 46 \\ \text { 10. Academy of Management Journal } & 45 \\ \text { 11. Organizational Behavior and Human } & 35 \\ \text { 12. Proceedings of the International Conference on IS } & 35 \\ \text { 13. Journal of Systems Management } & 32 \\ \text { 14. Interfaces } & 32 \\ \text { 15. Computerworld } & 32\end{array}$

Ranking based upon raw citation scores excluding self-citations
1. Management Science
133
2. Harvard Business Review
3. Communications of the $A C M$
4. MIS Quarterly
5. Administrative Science Quarterly
6. Datamation
7. Database
8. Decision Sciences
9. Academy of Management Journal
10. Sloan Management Review
11. Organizational Behavior and Human
12. Journal of Systems Management
13. Computerworld
14. Interfaces
15. Journal of Applied Psychology

Ranking based upon normalized citation scores including self-citations

1. Management Science

2. MIS Quarterly

3. Communications of the ACM

4. Harvard Business Review

5. Journal of the American Society for Information Sc.

6. Interfaces

7. Sloan Management Review

8. Decision Sciences

9. Datamation

10. Journal of Documentation

11. Artificial Intelligence

12. ACM Transactions an Database Systems

13. Database

14. Information and Management

15. Journal of Business

Ranking based upon normalized citation scores excluding self-citations
1. Management Science
2. MIS Quarterly
3. Communications of the ACM
4. Harvard Business Review $\quad 13.2$
5. Decision Sciences $\quad 6.4$
6. Interfaces 6.1
7. Sloan Management Review $\quad 6.0$
8. Datamation $\quad 5.5$
9. Journal of Documentation $\quad 5.5$
10. Artificial Intelligence $\quad 4.8$
11. ACM Transactions on Database Systems
12. Database $\quad 4.7$
13. Journal of Business $\quad 4.7$
14. Information and Management $\quad 4.2$
15. Administrative Science Quarterly 
journals in terms of how often it is cited by the others. The second focuses upon how interdependent the journals are by examining citation patterns between journal pairs.

\subsection{Determining the MIS core based upon cohesion}

Cohesion can be determined by examining the pattern of citations among the journals: those journals which do not substantially contribute to the common research (i.e., MIS) cannot be considered members of the MIS core. Table 3 contains the citation patterns among the 14 prospective core journals. For this table, rather than being restricted to articles referenced in Cooper (1988), all MIS research articles from all 14 journals from 1981 to 1985 are included. Articles in non-MIS journals (e.g. in Administrative Science Quarterly) were classified as MIS if they addressed the topics cited earlier in the MIS research survey by Cooper (1988). Following the approach used by Culnan and Swanson (1986), the intersection of independent classifications by two MIS researchers was employed to identify these MIS articles. (Interrater agreement was very high; Cohen's (1960) kappa $=.71$, $p<.001, N=852$.)

This resulted in a total of 277 articles published in the 14 journals, which makes 1479 citations to other articles in the 14 journals. Each row in Table 3 depicts the percentage of times that articles in that specific journal cite articles in the journals listed in the columns. For example, $28.1 \%$ of all citations in MIS Quarterly articles were to other articles in MIS Quarterly, while $12.9 \%$ of all citations in MIS Quarterly articles were to articles in Harvard Business Review. The bottom two rows present influence factors which are analogous to the impact factors used by Garfield (1972). These influence factors indicate the importance of each journal in terms of its role in providing information to other journals. The row marked "Total" is the summation of each column less the citations from a journal to itself. The row "Mean" is explained below.

With these total influence data, we can identify journals which do not influence (via citation) other journals and are thus not part of the MIS core. As illustrated, the Journal of the American Society for Information Science, the Journal of Documentation, and Artificial Intelligence clearly do not make significant contributions to the other journals. These three are thus candidates for being dropped from the core.

This evaluation is based upon one-way influences, where the number of citations from one journal to another are counted. Another view of journal cohesion can be derived by examining how strongly interconnected the journals are in terms of two-way influence, where mutual citations (journals citing each other) are counted.

A measure of this mutual citation strength used in bibliometric research relates the effect of each journal to the amount of communication entropy (disorder) existing in a system of journals publishing articles on the same subject (the Brillouin measure: Shaw, 1981, 1983; Pao, 1980; Boyce \& Martin, 1981). In this analysis, the data in Table 3 can be visualized as a connected graph, where the points represent the 14 different MIS journals and the lines, or edges, represent mutual citation relationships. For example, the line between the point representing Communications of the ACM and the point representing Management Science would indicate that Communications of the ACM cites Management Science $12.3 \%$ of the time and that Management Science cites Communications of the ACM 5.6\% of the time. It is the use of these mutual citation relationships as indicators of interjournal communication which enables us to use mathematical communication theory (Shannon \& Weaver, 1963) to measure the amount of communication entropy within a set of journals.

In order to construct such a connected graph, a mutual influence threshold must be identified. This threshold is used to determine if the two-way citation communication between any pair of journals is significant enough to be included as a line in the graph. Following a procedure suggested by Small and Koenig (1977), ${ }^{*}$ a reasonable threshold for our data is $5 \%$; significant mutual influence between two journals, $A$ and $B$, is thus defined

*If the threshold value chosen is zero, most of the 14 members would be connected into a single large cluster. However, if the maximum threshold value of one is chosen, the system of journals would break into 14 clusters, each having a single journal as a member. Thus, an appropriate intermediate threshold value is that suggested by Small and Koenig (1977) in which the largest cluster begins to break into smaller clusters. With our data, a $5 \%$ value was found to satisfy this criterion. 


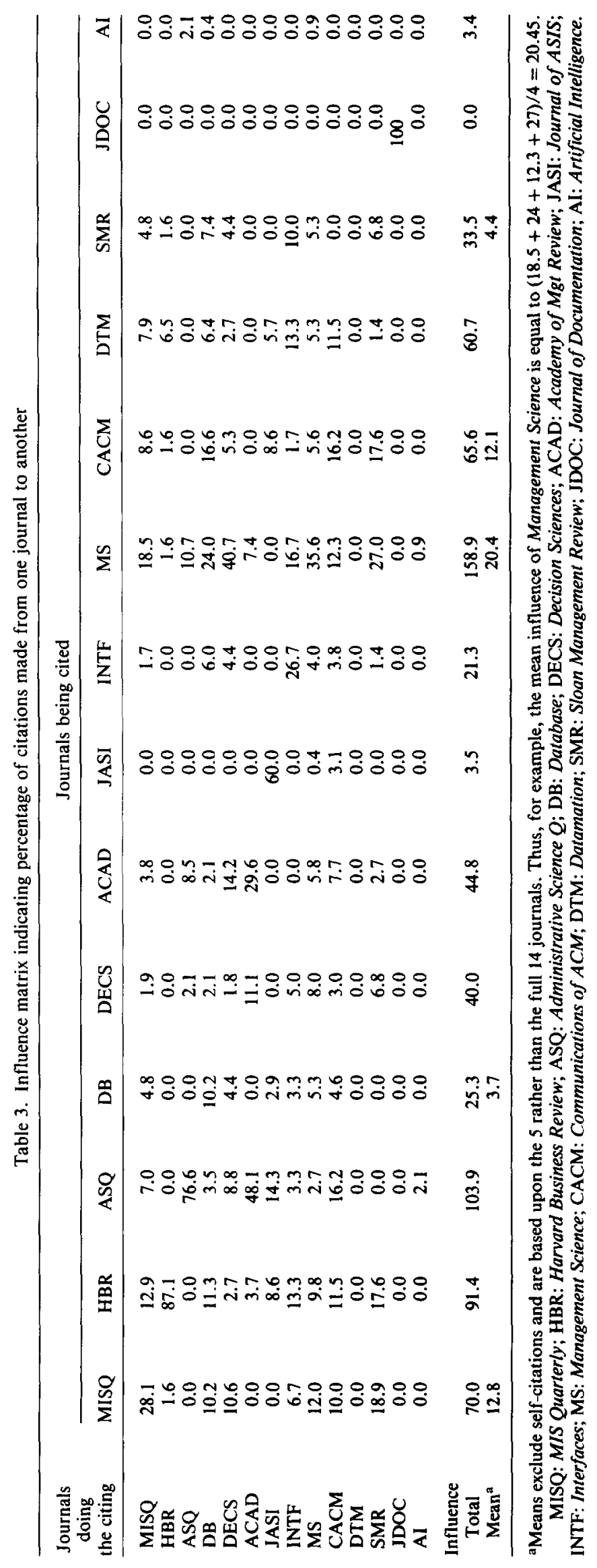


as having at least $5 \%$ of $A$ 's citations referencing $B$ and at least $5 \%$ of $B$ 's citations referencing $A$.

With this graph constructed, clusters of mutually dependent journals are found and the effect of each journal upon the total set entropy can be measured. This effect is calculated by determining the set's entropy with the journal as part of the set and then determining the set's entropy when the journal is excluded. If entropy increases when the journal is removed, the journal adds order to the system and can be said to be strongly connected within the system. Journals for which entropy decreases upon their removal are weakly connected. With the assumption stated earlier that members of the MIS core should be strongly connected, weakly connected journals are candidates for removal from the core.

The entropy measure is calculated as follows:

$$
I=\left(1 / \log _{10} 2\right)\left(\log _{10}\right)\left(N ! /\left(N_{1} ! N_{2} ! \ldots N_{s} !\right)\right)
$$

where $I$ is the measure of diversity (entropy) of the system of journals; $N$ is the total number of journals in the system; $N_{j}$ is the number of journals in the $j$ th cluster; $s$ is the total number of clusters found; $\left(1 / \log _{10} 2\right)$ converts the measure into bits.

With $I$ as the measure of entropy of the graph of the 14 MIS journals, and $I_{i}$ the measure of entropy of the graph with journal ${ }_{i}$ removed, the measure of journal $_{i}$ 's contribution to order is $I_{i}-I$.

Table 4 provides the results of these calculations for the 14 journals. As shown, the journals can be divided into the following three categories:

- Category 1: Journals Adding Order to the System Management Science

Communications of the ACM

- Category 2: Journals Having Little Effect on System Order Academy of Management Journal

Data Base

Decision Sciences

MIS Quarterly

Sloan Management Review

- Category 3: Journals Adding Disorder to the System

Administrative Science Quarterly

Artificial Intelligence

Datamation

Harvard Business Review

Interfaces

Journal of Documentation

Journal of the American Society for Information Science

Category 1 journals are strongly connected within the core and can be interpreted as synthesizers. On the other extreme, Category 3 journals are weakly connected, and their removal will increase the overall cohesiveness of the core.

These results are consistent with the earlier results that Artificial Intelligence, Journal of Documentation, and Journal of the American Society for Information Science do not belong in the core: each of these journals weakly influences MIS core journals and reduces the core's cohesion. In addition, Administrative Science Quarterly, Datamation, Harvard Business Review, and Interfaces though relatively influential, do not belong in the core because they are not strongly interconnected and reduce core cohesion.

Using bibliometric techniques which analyze the influence of journals through article use in research, we have established that a core of MIS journals exists (those in Categories 1 and 2, above) which are both influential to MIS research and cohesive. As mentioned in the introduction, a second dimension which is important for the determination of MIS journal influence concerns researchers' perceptions of journal influence. Hamilton and Ives (1983) surveyed MIS researchers in order to evaluate the perceived contributions of vari- 
Table 4. Entropy measure of order within the 14 journals

\begin{tabular}{lcc}
\hline Journals & $I_{i}$ & $I_{i}-21.24^{\mathrm{a}}$ \\
\hline Management Science & 27.37 & 6.13 \\
Communications of the ACM & 22.63 & 1.39 \\
Academy of Management Journal & 20.24 & -1 \\
Data Base & 20.24 & -1 \\
Decision Sciences & 20.24 & -1 \\
MIS Quarterly & 20.24 & -1 \\
Sloan Management Review & 20.24 & -1 \\
Administrative Science Quarterly & 17.65 & -3.59 \\
Artificial Intelligence & 17.65 & -3.59 \\
Datamation & 17.65 & -3.59 \\
Harvard Business Review & 17.65 & -3.59 \\
Interfaces & 17.65 & -3.59 \\
Journal of Documentation & 17.65 & -3.59 \\
Journal of the American Society... & 17.65 & -3.59 \\
\hline
\end{tabular}

a 21.24 is the value of entropy for the whole set $(I)$. Both $I$ and $I_{i}$ are determined with a threshold value of 0.05 as explained earlier.

ous journals to the MIS field. Comparing the journals in Categories 1 and 2 above with their survey results, we find that all the journals we have identified as making up the MIS core except for Decision Science and the Academy of Management Journal are perceived as highly contributing to the MIS field. Decision Science was perceived as a medium contributor and the Academy of Management Journal a low contributor. This accord between the our citation results and their perception results supports the notion of the existence of an MIS core.

\section{THE STABILITY OF THE MIS CORE OVER TIME}

The second issue to be addressed is whether the core is stable given the changing nature of MIS research. Core stability can be evaluated in terms of journal membership. That is, do evaluations at different points in time identify the same top influential journals? This question is examined by looking at the common occurrence of journals associated with these different rankings. First, a citation influence ranking of the top 10 journals based upon articles published in 1985 is constructed using methods similar to the Hamilton and Ives (1983) citation ranking which was based upon articles published in 1979.* As illustrated in Table 5, there is a $50 \%$ commonality when comparing journals chosen using the 1985 data (C,B,P-85) vs. the 1979 data (H \& I-CIT). This level of commonality persists with the additional comparisons of the 1980 survey of MIS researcher perceptions (H \& I-SURV), the publishing records of the top five MIS publishing institutions from 1977 through 1983 ( $V \& W$ ), and the MIS core journals described above using our 1981 through 1985 citation analyses $(\mathrm{C}, \mathrm{B}, \mathrm{P})$.

Comparing the results of multiple methods (citation analyses, publishing records, perception survey) over a 9-year period, there is considerable commonality regarding what MIS journals are most influential. However, the ranking by Doke and Luke (D \& L in Table 5)

*We used articles from 1985 in Cooper's (1988) survey to develop the following raw score influence ranking (in descending order); these 37 articles from 9 journals made 450 citations to 105 journals.
1. Management Science
2. Communications of the $A C M$
3. MIS Quarterly
4. Administrative Science Quarterly
5. Sloan Management Review
6. Academy of Management Journal
7. Harvard Business Review
8. Information and Management
9. Decision Sciences
10. Journal of Applied Psychology 
Table 5. Comparing the commonality of journals between rankings.

\begin{tabular}{lccccc}
\hline & H \& I-SURV & H \& I-CIT & V \& W & D \& L & C,B,P-85 \\
\hline C, B,P & $.60^{*}$ & $.46^{*}$ & $.58^{*}$ & $.27^{*}$ & $.67^{*}$ \\
H \& I-SURV & & $.67^{*}$ & $.67^{*}$ & .25 & $.40^{*}$ \\
H \& I-CIT & & & $.54^{*}$ & $.33^{*}$ & $.40^{*}$ \\
V \& W & & & .25 & $.43^{*}$ \\
D \& L & & & & .24 \\
\hline
\end{tabular}

Numbers in the table represent the proportion of journals which are shared by each pair of rankings. $N$ ranges from 9 to 17 depending upon the total number of different journals contained within each pair of rankings.

All asterisked proportions are significantly different from zero $(p<.01)$, significantly different from one $(p<.01)$ and NOT significantly different from .50 . Non-asterisked proportions are significantly different from zero $(p<.05)$, significantly different from one $(p<.01)$ and significantly different from $.50(p<.05)$.

C,B,P: Our choice of core journals; H \& I-SURV: Hamilton and Ives (1983) top 10 ranking based upon academics' perceptions of contributions to the MIS field; H \& I-CIT: Hamilton and Ivcs (1983) top 10 ranking based upon their citation analysis; V \& W: Vogel and Wetherbe (1984) top 10 ranking based upon the publishing records of the top five MIS publishing institutions; D \& L: Doke and Luke (1987) top 10 ranking based upon a survey of MIS academics' perceptions of importance/prestige; C,B,P-85: Our top 10 ranking using only 1985 data without self-citations.

seems to be different than all the rest. Though it could be argued that this difference is due to the recency of their survey (using 1986 data), this does not seem reasonable given the stability of rankings demonstrated above. In fact, Doke and Luke's findings may be due to response bias. They sent questionnaires to 243 business schools which were to be distributed to two MIS faculty at the professor level, two at the associate level, and two at the assistant level. Since only 82 questionnaires were returned, in the worst case, the response rate was $82 /(243 \times 6)=5.6 \%$; if, on average, only three questionnaires were distributed instead of six, the response rate would be $11.2 \%$.

There thus does seem to be a good degree of core stability. As one would expect in a changing field, levels of core stability can be identified. Examining the various rankings (excluding Doke and Luke) in more detail we find that Communications of the ACM, Management Science, and MIS Quarterly are common to all five. These three journals thus constitute the first level core: those which have constant core membership. A second level core includes those journals which are typically (but not always) in the core. This includes the following journals which were found in at least three out of the five rankings: Data Base, Datamation, Harvard Business Review, Information and Management, and Sloan Management Review. The third level core consists of marginal journals in the sense that they have a low probability of being in the core over time. This would include journals such as Decision Science, Academy of Management Journal, Transactions on Database Systems, etc.

\section{A RANKING OF JOURNAL INFLUENCE WITHIN THE CORE}

Having demonstrated the existence and stability of an MIS core, we turn to developing an influence ranking of its members. Core membership consists of journals which are influential, cohesive, and stable. We thus combine the analyses above which examined each of these criteria, excluding journals which are not influential, not cohesive, or not stable, and identify the following MIS core members (in alphabetical order):

Communications of the $A C M$

Data Base

Management Science

MIS Quarterly

Sloan Management Review 
We continue to define influence relative to the citing behavior of core MIS journals. As depicted in the last column in Table 3, the mean influence for each core journal is derived by ignoring the columns associated with all but the five core members and ignoring citations to itself. Thus, for example, the mean influence of Management Science is equal to $(18.5+24+12.3+27) / 4=20.45$. The resulting ranking is as follows:

\section{Journal}

Very Influential

1. Management Science

Influential

2. MIS Quarterly

3. Communications of the ACM

Less Influential

4. Sloan Management Review

5. Data Base
Mean Influence

20

12

4

4

This mean influence measure can be interpreted as a ratio scale which indicates the relative MIS research influence of the core journals. For example, by this scale, Management Science is more than four times as influential as Sloan Management Review, and each of the top three journals is at least three times as influential as any of the bottom two journals. There seem to be three categories of journal influence. Management Science is clearly a top influence journal, Communications of the ACM and MIS Quarterly fall into a second category, and the other journals belong in the last category. This ranking is significantly different than the Hamilton and Ives (1983) overall ranking of the importance of these journals (Kendall's Tau $=.40, p=.48, n=5$ ). Based upon our more sophisticated citation analyses and our focus upon research influence (rather than, e.g. submission preferences), we believe that our ranking is more representative of the MIS research core.

\section{CONCLUSION}

If a stable core of highly influential journals exists, then its identification and the ranking of its members in terms of research influence is important for funding university schools and departments; for faculty promotion, tenure, and salaries; and for awarding research grants. Using researchers perceptions of journal influence, publishing patterns of top MIS publishing universities, and citation analysis from prior research as well as our multimethod citation analyses, we found that a stable core of influential MIS journals does exist. In addition, our ranking of this core differs significantly from the Hamilton and Ives (1983) overall ranking as well as from other journal influence rankings. With its foundation in prior research and the methodological rigor of our analyses, we believe that our ranking is more appropriate for the purpose of evaluating MIS journals based upon their influence of MIS research than the prior rankings.

MIS field stability has implications for the long-term validity of this ranking. If the field is young and subject to considerable future change, current rankings may not provide an accurate picture in the future. This can result from changing editorial policies, the emergence of new journals, etc., which accompany a maturing field. These problems are exacerbated by the lag time between the emergence of a new journal and its appearance libraries and secondary indexing and abstracting services.

This concern is valid for MIS; there is significant evidence from our study as well as from prior work (e.g. Culnan \& Swanson, 1986; Farhoomand, 1987) that the field of MIS is young and changing. For example, in mature fields statistical regularities such as Bradford's Law (Bradford, 1948) describe the distribution of articles in journals devoted to a particular topic. According to this law, the number of top journals containing a given per- 
centage of the total citations in a subject area can be derived from the following formula (Brookes, 1969):

$$
n=s(N / s)^{p}
$$

where $n$ is the number of expected journals comprising $p$ percent of the total citations to all journals, $N$ is the total number of journals referenced, and $s$ is a constant.

Based upon this law, in a mature field, $42 \%$ of the citations made by the 146 articles used as a basis for our citation analysis should have referenced approximately 28 journals $\left(28=5(294 / 5)^{42}\right)$. The fact that only 14 journals were referenced implies that MIS is young, does not yet have enough influential journals, and can look forward to future change in journal existence and rankings. This notion is supported by the emergence of new MIS journals (Journal of Management Information Systems, Information Systems Research, Journal of Information Resource Management Systems, etc.), and by recent editorial decisions of established journals in related fields to publish more MIS articles (Information Processing and Management, International Journal of Information Management, etc.).

The impact of MIS field maturation upon MIS core membership and ranking may take many forms (Banville \& Landry, 1989). We will address three such maturation paths. The first assumes that as the field matures in will become more fractionated and tied to its three underlying referent fields: computer science, management science, and organization science (Culnan \& Swanson, 1986). If this occurs, then the future MIS core should be represented by journals in each of these referents. Because computer science and management science are already represented (Communications of the ACM and Management Science), one would expect that an organization science journal such as the Academy of Management Journal or Administrative Science Quarterly will become a core member.

The second form of MIS field maturation assumes that the field will emerge from its reference disciplines into an independent, coherent field (Culnan, 1987). If this is the case, barring extreme editorial changes in Communications of the ACM and Management Science, we would expect that future core membership would be dominated by journals devoted exclusively to MIS. For example, MIS Quarterly and Data Base may be joined by new MIS journals such as Information Systems Research or old MIS journals such as Information and Management or old journals with a new MIS focus such as Information Processing and Management.

The third form of MIS field "maturation" involves a degeneration of the field resulting in the "death of MIS" (Banville \& Landry, 1989). Banville and Landry argue against this from a philosophical point of view and our data support their argument. Though there are many MIS publication outlets representing a wide variety of research problems and representing methodologies which vary greatly in kind and rigor, our analyses demonstrate that journals which exert a major influence on MIS research are relatively few and have been relatively stable over time. In addition, though Banville and Landry suggest that MIS is fragmented into at least six fields, our entropy analysis which found only two synthesizing journals (Management Science and Communications of the $A C M$ ) suggests that MIS work tends to be limited to two or perhaps three fields. Thus, far from being an intellectual free-for-all, MIS has attained a sense of stability and does not seem to be in danger of dying.

\section{REFERENCES}

Banville, C., \& Landry, M. (1989). Can the field of MIS be disciplined? Communications of the ACM, 32, 48-60. Boyce, B.R., \& Martin, D. (1981). The Brillouin measure of an author's contribution to a literature in psychology, Journal of the American Society for Information Science, 32, 73-76.

Bradford, S.C. (1948). Documentation. London: Crosby Lockwood.

Brookes, B.C. (1969). Bradford's law and the bibliography of science. Nature, 224, 953-956.

Coe, R., \& Weinstock, I. (1984). Evaluating the management journals: a second look. Academy of Management Journal, 27, 660-666.

Cohen, J. (1960). A coefficient of agreement for nominal scales. Educational and Psychological Measurement, $20,37-46$. 
Cole, J.R., \& Cole, S. (1973). Social stratification in science. Chicago: University of Chicago Press.

Cooper, R.B. (1988). Review of management information systems research: a management support cmphasis. Information Processing and Management, 24, 73-102.

Culnan, M.J. (1986). The intellectual development of management information systems, 1972-1982: a co-citation analysis. Management Science, 32, 156-172.

Culnan, M.J. (1987). Mapping the intellectual structure of MIS, 1980-1985: a co-citation analysis. MIS Quarterly, $11,341-354$.

Culnan, M.J. \& Swanson, E.B. (1986). Research in management information systems, 1980-1984: points of work and reference. MIS Quarterly, 289-301.

Doke, E.R., \& Luke, R.H. (1987). Perceived quality of CIS/MIS journals among faculty: publishing hierarchies. The Journal of Computer Information Systems, 30-33.

Doreian, P. (1988). Measuring the relative standing of disciplinary journals. Information Processing and Management, $24,45-56$.

Farhoomand, A.F. (1987). Scientific progress of management information systems. Data Base, 18(4), 48-56.

Garfield, E. (1972). Citation analysis as a tool in journal evaluation. Science, 178, 471-479.

Goffman, W. (1985). Pragmatic approach to literature selection. In K.S. Warren (Ed.), Selectivity in information systems: survival of the fittest (pp. 117-143). New York: Prager Press.

Goffman, W., \& Pao, M.L. (1980). Retrieval of biomedical information for emerging interdisciplinary problems. Proceedings of the Fourth International Congress on Medical Librarianship, Belgrade, Yugoslavia, pp. 39-50.

Hamilton, S., \& Ives, B. (1982). Knowledge utilization among MIS researchers. MIS Quarterly, 61-77.

Hamilton, S., \& Ives, B. (1983). The journal communication system for MIS research. Data Base, 3-14.

Hirst, G. (1978). Discipline impact factors: A method for determining core journal lists. Journal of the American Society for Information Science, 29 (4), 171-182.

Hirst, G., \& Talen, N. (1977). Computer science journals: an integraded citation analysis. IEEE Transactions on Professional Communication, 20, 233-238.

Jensen, M.C., Long, J.B., Smith, C.W., Stulz, R.M., Warner, J.B. (1987). Ditation index ratings of the journal of financial economics. Journal of Financial Economics, 18, 3-6.

Koong, K.S., \& Weistroffer, H.R. (1988). A survey sent out by the Virginia Commonwealth University School of Business.

Moravcsik, M.J., \& Murugesan, P. (1975). Some results on the function and quality of citations. Social studies of science, $5,86-92$.

Pao, M.L. (1980). Co-authorship as a communication measure. Library Research, 2, 327-337.

Rice, R.E. (1990). Citation networks of communication and library and information science journals, $1978-1987$. ASIS '90: Proceedings of the 53rd Annual Meeting of the American Society for Information Science, 27, 208-313.

Rice, K.E., Borgman, C., Bednarski, D., \& Hart, P.J. (1989). Journal-to-journal citation data: issues of validity and reliability. Scientometric, $15,257-282$.

Salton, G., \& Bergmark, D. (1979). A citation study of computer science literature. IEEE Transactions on Professional Communication, 22, 285-298.

Servi, P.N., \& Griffth, B.C. (1980). A method for partitioning the journal literature. Journal of the American Society for Information Science, 31, 36-40.

Shaw, W.M. Jr. (1981). Information theory and scientific communication. Scientometrics, 3, 235-249.

Shaw, W.M. Jr. (1983). Statistical disorder and the analysis of a communication-graph. Journal of the American Society for Information Science, 34, 146-149.

Shannon, C.E., \& Weaver, W. (1963). The mathematical theory of communication. Urbana, IL: University of Illinois Press.

Small, H., \& Koenig, M. (1977). Journal clustering using a bibliographic coupling method. Information Processing and Management, 13, 277-288.

Smith, L.C. (1981). Citation analysis. Library Trends, 83-106.

Stohr, E.A. (1987). A survey sent out August 10, 1987 by the Information Systems Area, Graduate School of Business, New York University.

Subramanyam, K. (1975). Criteria for journal selection. Special Libraries, 66, 367-371.

Vogel, D.R., \& Wetherbe, J.C. (1984). MIS research: a profile of leading journals and universities, Data Base, 3-14. 